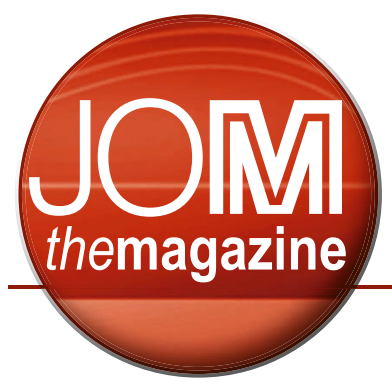

\section{member news}

Share the good news

about your professional

accomplishments!

Contact Kaitlin Calva,

JOM Magazine

Managing Editor,

at kcalva@tms.org.

Please note that only

news submitted by

current TMS members

will be considered.

\title{
Access Thousands of Papers in the Light Metals Library; Apply for the 2019 ELA Conference
}

\section{Light Metals Digital Library Provides Access to Decades of TMS Proceedings Papers}

In February 2019, TMS introduced a new member benefit - the Light Metals Digital Library. The new online collection houses more than 5,200 technical papers from TMS's signature Light Metals proceedings series, from the Light Metals symposia held at the TMS Annual Meeting \& Exhibition each year. The collection, which includes papers published from 1971 to 2010, can be searched by author, year, or title keyword, or browsed using the alphabetical list.

Individual articles from the collection can be purchased for $\$ 10$ each for TMS members or $\$ 25$ for nonmembers. TMS members can purchase a subscription to the library for $\$ 50$ per year, providing them access to the complete collection of articles. Subscription purchases can be made through the online TMS membership application/renewal form at www.tms .org/Portal/Membership/Join_Renew. Institutional subscriptions are also available_contact publications@tms.org

\section{for more information}

If you are not a TMS member, but are interested in obtaining member discounts on this and other resources and events, visit www.tms.org/Membership for more information on benefits and joining TMS.

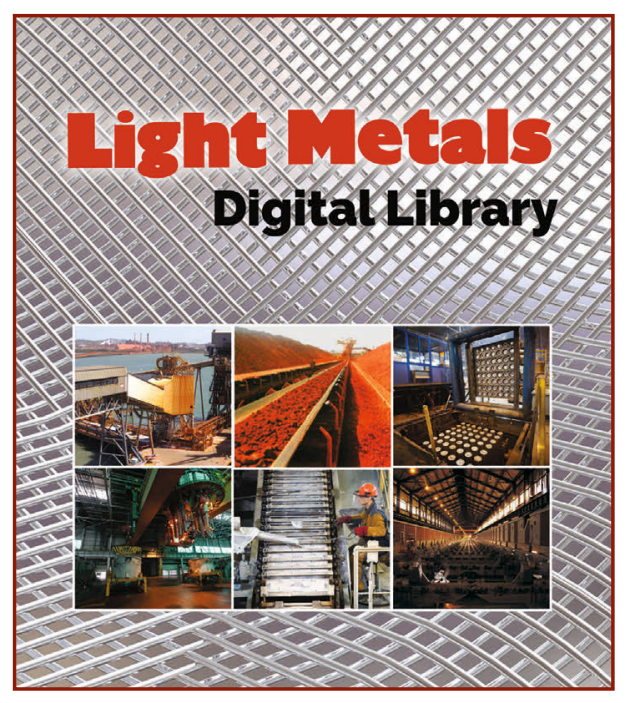

\section{Emerging Leaders Alliance Prepares Next Generation of TMS Leaders}

Each year, the Emerging Leaders Alliance (ELA) provides crossdisciplinary training for the future leaders of the science and engineering community. The conference series goes a step further than most academic programs by focusing on the strengthening nontechnical skills in a setting that allows them to obtain foundational, executive-level knowledge, while weaving themes of social responsibility and environmental stewardship throughout the training curriculum. As one of nine ELA partner societies, TMS was proud to send seven members, through the support of the TMS Foundation, to the 2018 ELA conference, held November 4-7, in Falls Church, Virginia.
"It was an excellent experience learning from leaders in industry as well as a great opportunity to network with individuals from all over the U.S. and several other countries," said Amber Ollis, Technology Analyst, TimkenSteel Corporation, and one of the TMS members who participated in the 2018 program. "The most valuable takeaway for me was learning that 'soft skills' are just as important in a manufacturing/metals industry as technical skills. Not an engineer by trade, I have sometimes devalued what I bring to my team and to TimkenSteel. Working together with highly intelligent and goalfocused individuals at ELA showed me that strengths and weaknesses vary across the board." 
"I found that I am more open to challenges and tackling new opportunities," Ollis continued, noting how the skills she learned at ELA have transferred to her current role. "I have attended quite a few conferences, and this is by far one of the more valuable and educational experiences. Along with recommending it to other team members in my own department, I would encourage others to look into this program."

Registration for the ELA conference is sponsored through the TMS Foundation for up to eight TMS young professional members each year. Applicants must be TMS members, typically ages $24-40$, with rising or current leadership positions in their organizations. To apply for a seat at the November 3-6, 2019, conference, send a letter of interest, one or two letters of recommendation, and a resume or curriculum vitae to Deborah Hixon, TMS Awards and Program Administrator, at hixon@tms.org. The deadline to apply is June 15.

More established TMS members can participate by donating to the TMS Foundation. Any level of support helps

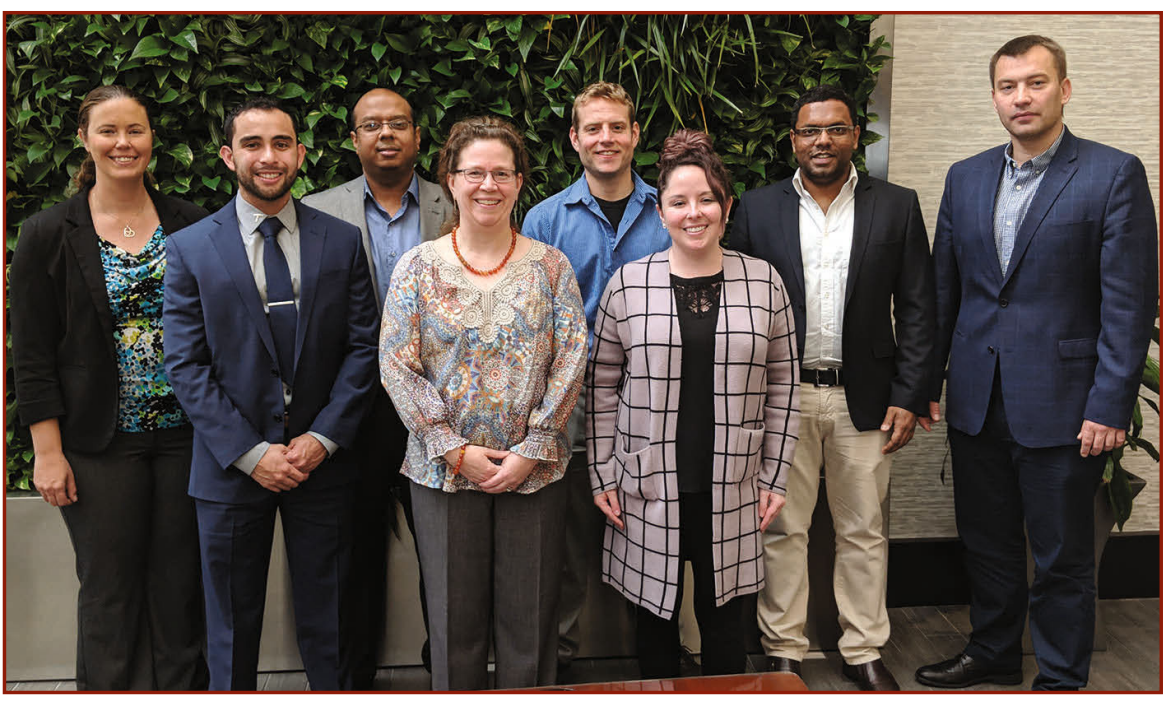

Attending the 2018 ELA program from TMS were: (back row, left to right) Clarissa Yablinsky, Los Alamos National Laboratory; Arif Mubarok, PPG Industries; Andrew Baker, Boeing; Ajith Chakkedath, Intel Corporation; and Konstantin Redkin, WHEMCO Inc.; (front row, left to right) Oscar Terrazas, ATI Specialty Materials; Deborah Hixon, TMS; and Amber Ollis, TimkenSteel Corporation.

ensure that future leaders of the minerals, metals, and materials community have access to this unique and valuable training program, in addition to other Foundation initiatives geared toward developing early career professionals. Visit www.TMSFoundation.org to make an online donation.

\section{Randy Beals Named Chair of ACRC}

TMS member Randy Beals began a twoyear appointment as the chair of the board of the Advanced Casting Research Center (ACRC) at Worcester Polytechnic Institute (WPI) in January 2019. Beals came to the ACRC after seven years with Magna International, where he worked most recently as a senior materials engineer and received the Magna Cosma Inspiring Innovator Award. He has brought his more than 25 years of experience working in aluminum and magnesium processing and product development in the automotive and aerospace industries to his new role at the ACRC.

Within TMS, Beals has been a JOM advisor and a member of the Aluminum, Magnesium, and Industrial Advisory Committees as well as the Light Metals Division Council.

\section{Corby Anderson Selected for Cypress Advisory Board}

Corby Anderson has recently joined the Cypress Development Corp.'s Technical Advisory Board. Anderson, currently the Harrison Western Professor in the Kroll Institute for Extractive Metallurgy at the Colorado School of Mines, offers more than 40 years of industrial, research, and educational experience in extractive metallurgy, mineral processing, waste minimization, and recycling to his new position at Cypress.
A TMS member for nearly 25 years, Anderson has been involved in the Extraction \& Processing Division (EPD) Council and several other technical committees. In 1996, he received the EPD Technology Award and later the 2017 EPD Distinguished Lecturer Award. As a part of the honors for the latter award, Anderson presented a lecture at the TMS 2017 Annual Meeting \& Exhibition in San Diego, California.

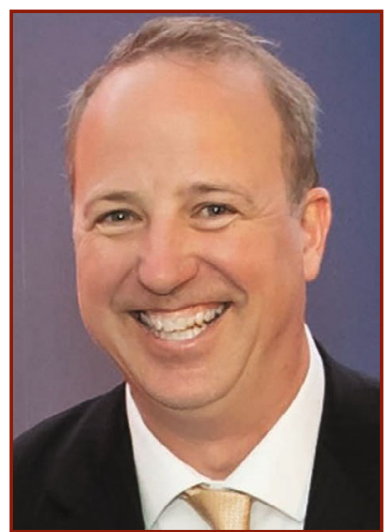

Randy Beals (Photo courtesy of WPI.)

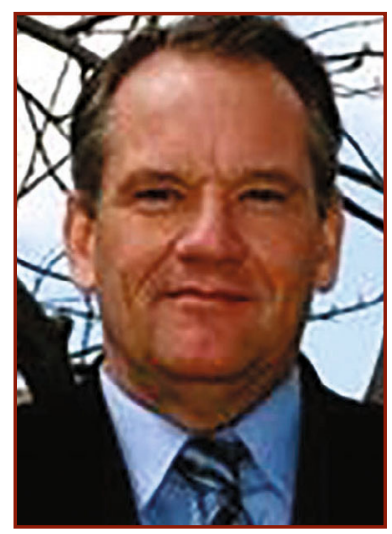

Corby Anderson 